\title{
Natural Substances for the Synthesis of Silver Nanoparticles against Escherichia coli: The Case of Megaphrynium macrostachyum (Marantaceae), Corchorus olitorus (Tiliaceae), Ricinodendron heudelotii (Euphorbiaceae), Gnetum bucholzianum (Gnetaceae), and Ipomoea batatas (Convolvulaceae)
}

\author{
Francois Eya'ane Meva, ${ }^{1}$ Cecile Okalla Ebongue, ${ }^{2,3}$ Simone Véronique Fannang, \\ Marcelle Loretta Segnou, ${ }^{1}$ Agnes Antoinette Ntoumba, ${ }^{4}$ Philippe Belle Ebanda Kedi, ${ }^{4}$ \\ Rudy-Evrard Njike Loudang, ${ }^{1}$ Andre Yonga Wanlao, ${ }^{5}$ Emmanuel Roland Mang, \\ and Emmanuel Albert Mpondo Mpondo ${ }^{1,6}$ \\ ${ }^{1}$ Department of Pharmaceutical Sciences, Faculty of Medicine and Pharmaceutical Sciences, University of Douala, Douala, Cameroon \\ ${ }^{2}$ Department of Biological Sciences, Faculty of Medicine and Pharmaceutical Sciences, University of Douala, Douala, Cameroon \\ ${ }^{3}$ Clinical Biology Laboratory, General Hospital of Douala, Douala, Cameroon \\ ${ }^{4}$ Department of Animal Biology and Physiology, Faculty of Science, University of Douala, Douala, Cameroon \\ ${ }^{5}$ Department of Chemistry, Faculty of Sciences, University of Douala, Douala, Cameroon \\ ${ }^{6}$ Department of Pharmacotoxicology and Pharmacokinetics, University of Yaounde I, Yaounde, Cameroon
}

Correspondence should be addressed to Francois Eya’ane Meva; mevae@daad-alumni.de

Received 11 November 2016; Revised 19 December 2016; Accepted 21 December 2016; Published 30 January 2017

Academic Editor: Xuping Sun

Copyright (C) 2017 Francois Eya'ane Meva et al. This is an open access article distributed under the Creative Commons Attribution License, which permits unrestricted use, distribution, and reproduction in any medium, provided the original work is properly cited.

\begin{abstract}
The development of drug-resistant strains is rising and the search for new and novel ways of fighting new or reemerging microbes goes on. A hope of treating such multidrug-resistant infections came from plants mediated nanoparticles since nature is a generous source which provides a variety of chemical compounds that can be used for new drug discovery. Silver nanoparticles are reported to possess antiviral, antibacterial, antifungal, antiparasitic, larvicidal activity and anticancer properties. We reported green synthesis of silver nanoparticles mediated food plants Megaphrynium macrostachyum, Corchorus olitorus, Ricinodendron heudelotii, Gnetum bucholzianum, and Ipomoea batatas and their antibacterial efficacy against the Enterobacteriaceae Escherichia coli. The nature and size of the obtained nanoparticles are discussed as well as their Minimum Inhibitory Concentration (MIC) and the Minimum Bactericide Concentration (MBC) values considering their application in medical industry.
\end{abstract}

\section{Introduction}

Increasing resistance against antibiotics is a burning health problem and there is an urgent need to improve the existing drugs or find new, novel strategies to overcome this problem [1]. Nanoparticles, generally considered as particles with a size of up to $100 \mathrm{~nm}$, exhibit completely new or improved properties as compared to the larger particles of the bulk material that they are made up of [2]. One of the most challenging goals in nanoparticle research is to develop successful protocols for the large-scale, simple, and (possibly) lowcost preparation of morphologically pure nanoparticles with identical properties. Additionally, nanoparticles should be easily stored and manipulated without losing their properties 
TABLE 1: Biochemical profile of selected Escherichia coli strain.

\begin{tabular}{lcccccccccccccccc}
\hline Character & ODC & IND & ADH & $\beta$ NAG & LDC & $\beta$ GAL & URE & GLU & LARL & SAC & GAT & LAR & 5KG & DARL & LIP & $\alpha$ GLU \\
\hline Result & - & + & - & - & + & - & - & + & - & + & + & + & - & - & - & - \\
\hline Character & RP & $\alpha$ GAL & $\beta$ GLU & TRE & MAN & RHA & MAL & INO & ADO & CEL & PLE & SOR & MNT & ASPA & $\beta G U R$ & $\alpha M A L$ \\
\hline Result & + & + & - & + & + & + & + & - & - & - & - & + & - & - & + & - \\
\hline
\end{tabular}

ODC: ornithine decarboxylase; ADH: arginine; LDC: lysine decarboxylase; URE: urease; LARL: L-arabitol; GAT: galacturonate; 5KG: 5-ketogluconate; LIP: lipid; RP: red phenol; $\beta$ GLU: beta-glucosidase; MAN: mannitol; MAL: maltose; ADO: adonitol; PLE: palatinose; $\beta$ GUR: beta-glucuronidase; MNT: malonate; IND: indole; $\beta$ NAG: $N$-acetyl-beta-glucosaminidase; $\beta$ GAL: beta-galactosidase; GLU: glucose; SAC: saccharose; LARA:L-arabinose; DARL: D-arabitol; $\alpha$ GLU: alpha-glucosidase; $\alpha$ GAL: alpha-galactose; TRE: trehalose; RHA: rhamnose; INO: inositol; CEL: cellobiose; SOR: sorbitol; $\alpha$ MAL: alpha-maltosidase; ASPA: L-aspartic arylamidase acid.

TABLE 2: Susceptibility profile of selected Escherichia coli strain.

\begin{tabular}{lcccccccc}
\hline ATB & AMP & AMOX & TIC & PIP & CEFA & CEFO & CEFTA & ERTA \\
\hline Result & $\mathrm{R}$ & $\mathrm{R}$ & $\mathrm{R}$ & $\mathrm{R}$ & $\mathrm{R}$ & $\mathrm{R}$ & $\mathrm{R}$ \\
\hline ATB & IMI & AMI & GENTA & TOBRA & Ac NA & CIPRO & OFLO & NITRO \\
\hline Result & $\mathrm{S}$ & $\mathrm{R}$ & $\mathrm{R}$ & $\mathrm{S}$ & $\mathrm{R}$ & $\mathrm{R}$ & $\mathrm{R}$ & $\mathrm{R}$ \\
\hline
\end{tabular}

AMP: ampicillin, AMOX: amoxicillin, TIC: ticarcillin, PIP: piperacillin, CEFA: cefalotin, CEFO: cefotaxime, CEFTA: ceftazidime, ERTA: ertapenem, IMI: imipenem, AMI: amikacin, GENTA: gentamicin, TOBRA: tobramycin, Ac NA: nalidixic acid, CPRO: ciprofloxacin, OFLO: ofloxacin, and NITRO: nitrofurantoin.

[3]. With the rise in antibiotic resistance in recent years and the development of fewer new antibiotics, research has begun to focus on these antibacterial nanoparticles as potential new medical tools $[4,5]$. The most common methods for preparing most of these nanoparticles are wet-chemical techniques, which are generally low-cost and high-volume. However, the need for toxic solvents and the contamination from chemicals used in nanoparticle production limit their potential use in biomedical applications [6]. Therefore a "green," nontoxic way of synthesizing metallic nanoparticles is needed in order to allow them to be used in a wider range of industries. This could potentially be achieved by using biological methods [4] .

Research and development in biomedicine utilizes past cited history of natural products used in ancient world [9]. The antimicrobial effect of various metals and their salts has been known for centuries [10]. The Phoenicians used silver vessels to preserve water, wine, and vinegar during their long trips, while ancient Egyptians believed that silver powder provided beneficial healing and antidisease properties [11]. Recent efforts have been focused on developing new green chemistry methods of silver nanoparticles synthesis with the advantage of using natural products and avoiding toxic reducing agents, organic solvents, and wasteful purifications with high cytotoxic residuals [10]. Molecules produced by living organisms such as bacteria, fungi, or plants can replace the reducing and capping agents for the production of nanoparticles.

Herbs have been an integral part of our therapeutic consideration since thousands of years but are still under investigation and have become a part of biomedical research laboratories. Several medicinal plants and their bioactive molecules has been studied and tested for their efficacy against various diseases [9]. A number of secondary metabolites like phenols, flavonoids, glycosides, alkaloids, saponins, triterpenes, and so forth produced by plants are pharmacologically active. The added advantage of using natural products therapeutically is that they are safe, economical, and with lesser side effects [1]. The plants used in this research are Megaphrynium macrostachyum (Marantaceae), Corchorus olitorus (Tiliaceae), Ricinodendron heudelotii (Euphorbiaceae), Gnetum bucholzianum (Gnetaceae), and Ipomoea batatas (Convolvulaceae). They have been selected due to their involvement in food supply. The synthetics optimizations and the suitability of these plants parts to produce silver nanoparticles have been described in our previous reports $[7,8,12]$. We describe herein the uses of the obtained silver nanoparticles as antimicrobial agent against Escherichia coli.

\section{Material and Methods}

2.1. Selection of Bacteria. Escherichia coli strains were isolated from urine sample in the bacteriology unit, of the General Hospital laboratory, Douala, Cameroon. These strains were identified by automatic colorimetric reading on VITEK $2^{\mathrm{TM}}$ (BIOMERIEUX SA, France) after plating into Eosin Methylene Blue agar and incubation at $37^{\circ} \mathrm{C}$ for 24 hours. Susceptibility tests were performed by dilution in cards, an automatic turbidimetric reading on VITEK 2. The biochemical profile and susceptibility are presented in Tables 1 and 2 , respectively.

2.2. Plant Extracts. Fresh leaves of Megaphrynium macrostachyum (Benth. \& Hook. f.) Milne-Redh. (Marantaceae) deposit number 10000/SRF Cam, Corchorus olitorus Linn (Tiliaceae) deposit number 14725/SRF Cam, Gnetum bucholzianum Engl. (Gnetaceae) deposit number 59887/HNC, and Ipomoea batatas (L.) Lam (Convolvulaceae) deposit number 26429/SRF Cam and seed kernels of Ricinodendron heudelotii (Baill) Pierre Pax (Euphorbiaceae) deposit number 19695/SRF Cam were procured from local market, Douala, Cameroon, and identified at the National Herbarium of Cameroon. The organic materials were surface cleaned with running tap water followed by deionized water to remove 
TABLE 3: Silver nanoparticles dilutions $(\mu \mathrm{g} / \mathrm{mL})$.

\begin{tabular}{lccccccc}
\hline Silver organic nanoparticles & C1 & C2 & C3 & C4 & C5 & C6 & C7 \\
\hline Ag-Megaphrynium macrostachyum & 4,12 & 2,06 & 1,03 & 0,515 & 0,257 & 0,128 & 0,0643 \\
Ag-Corchorus olitorus & 16,5 & 8,25 & 4,125 & 2,06 & 1,031 & 0,515 & 0,257 \\
Ag-Gnetum bucholzianum & 54 & 27 & 13,5 & 6,75 & 3,37 & 1,687 & 0,843 \\
Ag-Ipomoea batatas & 21,2 & 10,6 & 5,3 & 2,65 & 1,325 & 0,662 & 0,331 \\
Ag-Ricinodendron heudelotii & 13,5 & 6,75 & 3,37 & 1,687 & 0,843 & 0,421 & 0,21 \\
\hline
\end{tabular}

all the dust and unwanted visible particles. Aqueous plant extracts were prepared by boiling $10 \mathrm{~g}$ organic material in $200 \mathrm{ml}$ deionized water for $5 \mathrm{~min}$ at $80^{\circ} \mathrm{C}$. The extract was filtered through Whatman number 1 filter paper to remove particulate matter and get clear solutions and stored at $4^{\circ} \mathrm{C}$ for further use, being usable for one week due to the gradual loss of plant extract viability for prolonged storage [8].

\subsection{Synthesis of Silver Nanoparticles. Silver nitrate $\left(\mathrm{AgNO}_{3}\right)$} was obtained from Sigma-Aldrich chemicals Germany. Deionized water was used throughout the reactions. All glass wares were washed with dilute nitric acid $\left(\mathrm{HNO}_{3}\right)$ and deionized water and then dried in hot air oven. A solution of $\mathrm{AgNO}_{3} 10^{-3} \mathrm{M}$ was prepared in deionized water. As a standard procedure, $10 \mathrm{~mL}$ of organic material extract was added to $50 \mathrm{~mL}$ of $10^{-3} \mathrm{M}$ aqueous $\mathrm{AgNO}_{3}$ solution, hand shaken during $1 \mathrm{~min}$, and incubated at room temperature in the dark to minimize the photoactivation of silver nitrate. The reactions were made under static conditions. First hour of reaction was monitored by ultraviolet visible spectroscopy of $2.5 \mathrm{ml}$ of the reaction suspension using an UV-visible Uviline 9100 spectrophotometer operating at $1 \mathrm{~nm}$ resolution with optical length of $10 \mathrm{~mm}$. Concentrations were determined by centrifugation after 24 hours of incubation. UV-visible analysis of the reaction mixture was observed for a period of 300 s. Powder X-ray diffraction measurements were carried out using a PANalytical Empyrean Serie $2 \mathrm{X}$-ray diffractome-

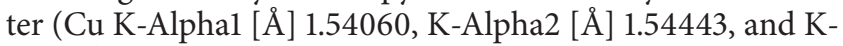
Beta $[\AA] 1.39225)$ by preparing a thin film of the silver-organic nanopowder on silicon substrate.

\subsection{Determination of the Minimum Inhibitory Concentration} (MIC) and the Minimum Bactericide Concentration (MBC). The silver nanoparticles solutions have been screened for sterility by incubation 48 hours at $37^{\circ} \mathrm{C}$ on Eosin Methylene Blue (EMB) agar plates. Twenty-four hours cultures of the Escherichia coli strains diluted in $4 \mathrm{ml}$ of saline water were used to prepare a suspension of $0,5 \mathrm{McF}$ according to the breakpoints of the French Society of Microbiology. This suspension was diluted to $1 / 10$ th to obtain a concentration of inoculum test for about $1,5 \times 10^{6}$ germs $/ \mathrm{mL}$ [13]. The microdilution broth method was used to obtain the Minimum Inhibitory Concentration (MIC) and the Minimum Bactericide Concentration (MBC) of colloidal silver nanoparticle solution. The MIC is defined as the smallest concentration of silver nanoparticles for which no growth is visible to the naked eye [14] and the MBC the smallest concentration of silver nanoparticles for which no bacterial growth was observed on Eosin Methylene Blue agar [13]. In a microplaque numbered from $\mathrm{C} 1$ to $\mathrm{C} 7$ and a control $\mathrm{Tc}$, $100 \mu \mathrm{l}$ of the inoculums test, $100 \mu \mathrm{L}$ of Mueller Hinton broth, and, with the exception of the control tube $\mathrm{T}$, concentrations of silver nanoparticles following a dilution of geometric progression of reason $1 / 2$ as reported in Table 3 were introduced successively. The microplaque was incubated at $37^{\circ} \mathrm{C}$ and after 24 hours, ten $\mu \mathrm{L}$ of each dilution was then inoculated on Eosin Methylene Blue agar and incubated at the time $t_{0}=0$ hours, $t_{1}=24$ hours, and $t_{2}=48$ hours, at $37^{\circ} \mathrm{C}$, at the rate of two plates per dilution [14].

The cloudiness was then assessed visually. The lowest concentration at which the cloudiness occurred was taken as the MIC value. To obtain MBC values, samples were taken from the pots showing no growth, spread onto nutrient agar plates, and incubated at $37^{\circ} \mathrm{C}$ for 24 hours. MBC was determined based on $3 \log$ decrease in the viable population of the pathogens.

\section{Results and Discussion}

3.1. Synthesis. A green chemistry approach, which protects the environment, has been used to generate the silver nanoparticles. Thus, all organic materials were cleaned with running tap water followed by deionized water to remove all the dust and unwanted visible particles. Aqueous plant extracts of dissolved reductants and capping molecules were prepared by boiling $10 \mathrm{~g}$ organic material in $200 \mathrm{ml}$ deionized water for $5 \mathrm{~min}$ at $80^{\circ} \mathrm{C}$. The method is generally used to synthetize silver nanoparticles and has been retained for this work $[7,8,12]$. The silver nanoparticles mediated leaves of Megaphrynium macrostachyum, Corchorus olitorus, Gnetum bucholzianum, and Ipomoea batatas and seed kernels of Ricinodendron heudelotii are therefore obtained in the same synthetic conditions. Hours are required for an ionic silver reduction using the seed kernels of Ricinodendron heudelotii. The other plant material extract reacts completely above one hour of reaction time.

3.2. Ultraviolet Visible Spectroscopy. Ultraviolet visible spectroscopy is a valuable tool to characterize nanoparticles. The technique is fundamental to ascertain the formation of nanoparticles giving indications such as formation, size growth, or shape. Generally, the formation of nanoparticles begins immediately after the contact of plant extract and $\mathrm{AgNO}_{3}$ solution. The colour of the mixture extracts and silver nitrate changes from clear to yellow and dark brown due to formation of plasmons at the colloid surface, thus 


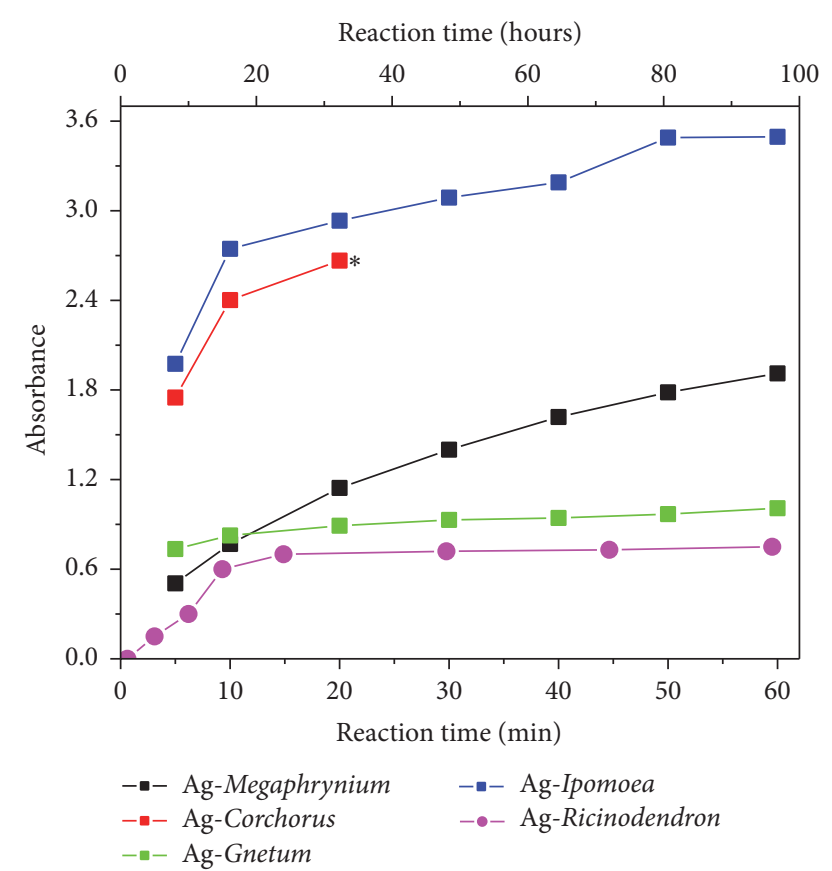

FIGURE 1: Evolution of the maximum of absorbance of the synthetized nanoparticles from Megaphrynium macrostarchyum, Corchorus olitorus, Gnetum bucholzianum, and Ipomoea batatas during one hour of reaction. Ricinodendron heudelotii mediated silver nanoparticles synthesis requires hours of contact time (magenta). ${ }^{*}$ Ag-Corchorus silver nanoparticles absorbances are over 4 a.u. after 20 minutes of reaction.

indicating the synthesis and growth of silver nanoparticles. Based on visual observation, few seconds are necessary to reduce ionic silver to silver nanoparticles when the reaction is mediated with extracts of Megaphrynium macrostarchyum and Corchorus olitorus. Such a rapid reductions in two minutes as been observed in 2013 by Awwad et al. using a carob leaf extract [15]. The lowest reduction rate is found for the synthesis of silver nanoparticles from Ricinodendron heudelotii seed kernel extract where twenty-four hours is necessary for the reduction. Figure 1 presents the monitoring of the maximum absorbance of the synthetized nanoparticles from Megaphrynium macrostachyum, Corchorus olitorus, Gnetum bucholzianum, and Ipomoea batatas during the first hour of reaction. In the case of the synthesis of silver nanoparticles mediated Corchorus olitorus leaf extract the absorbance is above 4 , the limit of the spectrometer after 20 minutes reflecting a very rapid reduction of the ionic silver. The plant extracts used are able to reduce ionic silver and to stabilize the obtained nanoparticles which have been usable over 3 months.

3.3. X-Ray Diffraction. Powder XRD, one of the most important characterization tools used in solid state chemistry, is used to prove the formation of crystalline phases and to calculate the particle size. The patterns of the prepared nanoparticles from Ricinodendron heudelotii seed kernels extract and Gnetum bucholzianum leaf extract are shown in Figures 2 and 3. Both pattern is one of generated silver

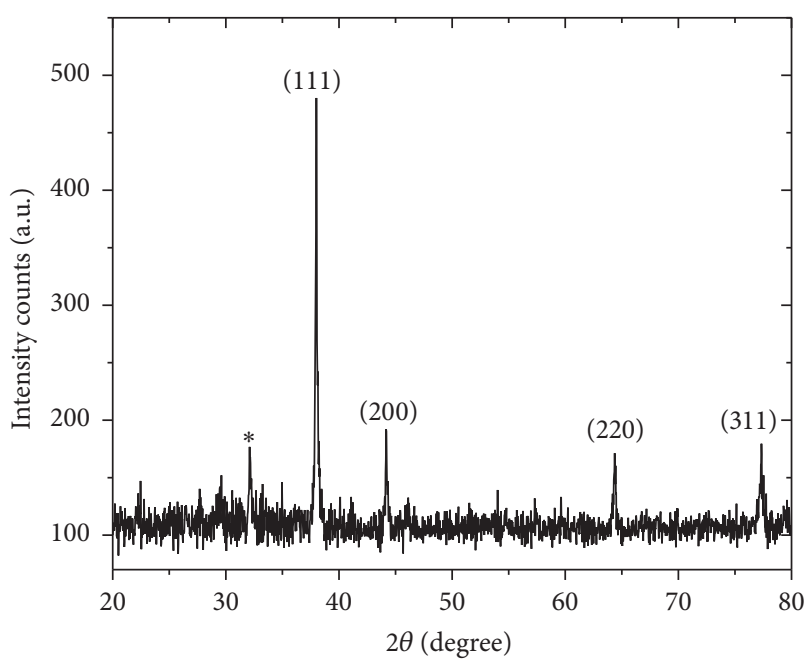

FIGURE 2: XRD pattern of the silver nanoparticles from Ricinodendron heudelotii. ${ }^{*}$ Undefined silver-extract phase.

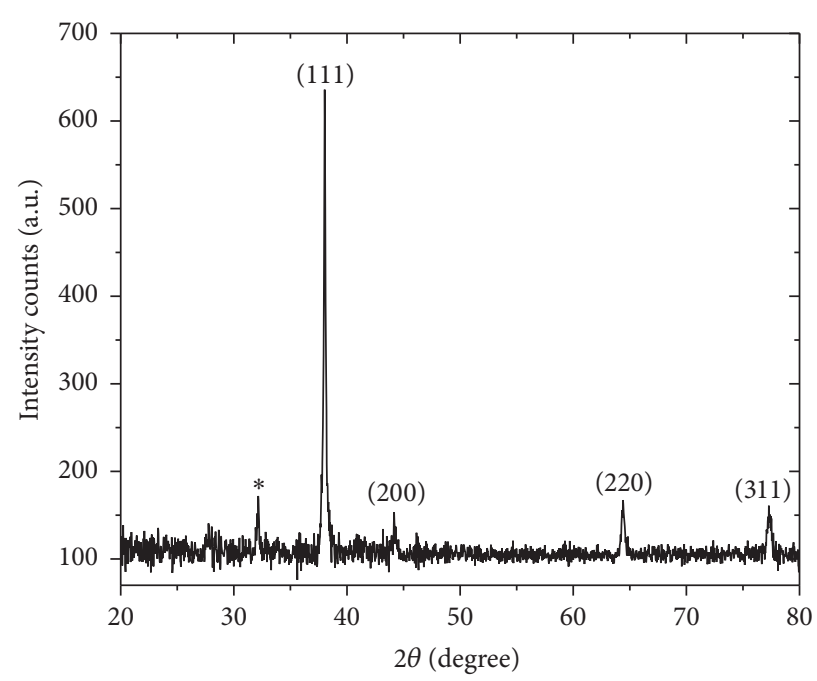

FIGURE 3: XRD pattern of the silver nanoparticles from Gnetum bucholzianum. * Undefined silver-extract phase.

nanoparticles compatible with the cubic phase of Ag with diffraction points at $2 \theta$ values of $38^{\circ}, 44.1^{\circ}, 64.4^{\circ}$, and $77.3^{\circ}$ which can be indexed to the (111), (200), (220), and (311) planes of the face centered cubic (FCC) structure, respectively (JCPDS file: 65-2871). The average crystallite size of the synthesized NP was determined using the Debye-Scherrer equation:

$$
D_{v}=\frac{K \lambda}{\beta \cos \theta},
$$

where $D v$ is the average crystalline size; $K$ is a dimensionless shape factor, with a value close to unity $(0.9) ; \lambda$ is the wavelength of $\mathrm{Cu} K \alpha ; \beta$ is the full width at half-maximum of the diffraction peaks; and $\theta$ is Bragg's angle.

To calculate the average crystalline particle size of the synthesized nanoparticles, the most intense peaks of Ag have 
been preferred [8]. The calculated average crystalline particle size of the Ag-Ricinodendron was found to be $89.0 \mathrm{~nm}$, while $67.4 \mathrm{~nm}$ has been found for the Ag-Gnetum nanoparticles. The intense and narrow diffraction peaks revealed the crystalline nature of the synthesized nanoparticles [16].

Both patterns identification shows the formation crystals of silver. The signal at the $2 \theta$ value of 32.1 in both diffractograms could be attributed to the crystallization of bioorganic phase that occurs on the surface of the nanoparticle [17]. Silver nanoparticles pattern of Megaphrynium macrostachyum (Marantaceae), Corchorus olitorus (Tiliaceae), and Ipomoea batatas (Convolvulaceae) has been obtained in previous work $[8,12]$. Using these leaf extracts, silver nanoparticles of the type Ag@AgCl have been obtained. The calculated average sizes are inside Table 4. Why Ag@AgCl or Ag nanoparticles are generated using the different organic materials is unclear and has not been further investigated in this report.

3.4. Microbiological Assays. The resistance of human pathogens to the commercially available antimicrobial agents and antibiotics has raised the need to explore new natural and inorganic substitutes to overcome the problem [17]. Le et al. [18] demonstrated that Ag nanoparticles get attached to the cell surface of Escherichia coli and then penetrated into the cell, destroyed the cell cytoplasm, and killed the organism. Le et al. [18] also found that Ag nanoparticles significantly increase the cell permeability and affect the proper transport through plasma membrane. It seems that sulphur and phosphorus containing proteins or enzymes or phosphorous moiety of DNA of bacterial system may be affected by the Ag nanoparticles which lead to the inhibition of enzyme system of the organism [19].

In this study, no bacterial growth was observed on Eosin Methylene Blue (EMB) agar plates after 48 hours of incubation of all synthesized silver nanoparticles, evidence that the suspension contained no germs before the test. Table 4 presents the results of the in vitro toxicity test of the silver-organic nanoparticles on Escherichia coli. The value of MIC and MBC shows that the silver nanoparticles are highly effective to annihilate the apparition of Escherichia coli strain. The lowest value of MIC was obtained from silver nanoparticles mediated Megaphrynium macrostachyum leaf extract $(0.515 \mu \mathrm{g} / \mathrm{mL})$ while the lowest MBC was obtained with silver nanoparticles mediated Gnetum bucholzianum leaf extract $(1,687 \mu \mathrm{g} / \mathrm{mL})$. The MIC and MBC values are identical for the silver nanoparticles obtained from Ipomoea batatas and Gnetum bucholzianum. All values are consistent with the literature on antibacterial activity of plant mediated silver nanoparticles [20, 21]. Silver chloride nanoparticles have proved efficacy as antibacterial agent [22]. Silver nanoparticles generated in this work, alone and in mixtures with silver chloride nanoparticles, are effective antibacterial agents too. The antibacterial activity exhibited by silver nanoparticles depends on $\mathrm{AgNO}_{3}$ concentration. A low metal concentration enhances the antibacterial activity because smaller particles have larger surface area available for interaction and will give more bactericidal effect than the larger particles [23]. No reasonable significant efficacy
TABle 4: Type and powder diffraction based-size of the silver nanoparticles used.

\begin{tabular}{lcc}
\hline Organic material & $\begin{array}{c}\text { Type and size of } \\
\text { particles }\end{array}$ & References \\
\hline Megaphrynium macrostarchyum & $\operatorname{Ag} 33.7 \mathrm{~nm} \mathrm{AgCl}$ & [7] \\
& $\begin{array}{c}40.2 \mathrm{~nm} \\
\text { Cg } 30.0 \mathrm{~nm} \mathrm{AgCl} \\
37.9 \mathrm{~nm}\end{array}$ & \\
Corchorus olitorus & $\mathrm{Ag} 67.3 \mathrm{~nm} \mathrm{AgCl}$ & \\
& $37.9 \mathrm{~nm}$ & {$[8]$} \\
Ipomoea batatas & $\mathrm{Ag} 89.0 \mathrm{~nm}$ & This work \\
Ricinodendron heudelotii & $\mathrm{Ag} 67.4 \mathrm{~nm}$ & This work \\
Gnetum bucholzianum & &
\end{tabular}

TABLE 5: CMI and CMB of the synthesized nanoparticles $(\mu \mathrm{g} / \mathrm{mL})$.

\begin{tabular}{lcc}
\hline Nanoparticles & CMI & CMB \\
\hline AgNPs from Megaphrynium macrostachyum & 0,515 & 4,12 \\
AgNPs from Corchorus olitorus & 8,25 & 16,5 \\
AgNPs from Ipomoea batatas & 5,3 & 5,3 \\
AgNPs from Ricinodendron heudelotii & 1,68 & 6,75 \\
AgNPs from Gnetum bucholzianum & 1,687 & 1,687 \\
\hline
\end{tabular}

differences were here observed between the sites of $30 \mathrm{~nm}$ and $90 \mathrm{~nm}$ using different silver nanoparticles mediated plants extracts. The CMI and CMB data of the synthesized nanoparticles are shown in Table 5.

\section{Conclusion}

Nanomaterials are providing solutions to many technological and environmental challenges in the areas of solar energy conversion, catalysis, medicine, and water treatment. In our study, we have investigated the synthesis of silver nanoparticles in a simple, cost-effective, and green approach using plants extracts of Megaphrynium macrostachyum, Corchorus olitorus, Ricinodendron heudelotii, Gnetum bucholzianum, and Ipomoea batatas. The obtained nanoparticles were composed of crystalline silver for Ricinodendron heudelotii and Gnetum bucholzianum and silver chloride and silver for the other plant extracts. Antimicrobial activity of the nanoparticles ranged from $30 \mathrm{~nm}$ to $80 \mathrm{~nm}$ against Escherichia coli and was evaluated by obtaining the MIC and MBC values of few $\mu \mathrm{g} / \mathrm{mL}$. Thus, biosynthesized silver nanoparticles can find immense application in the field of biomedical appliances and formulation of antimicrobial agents and in combination with antibiotics.

\section{Competing Interests}

The authors declare no competing interests.

\section{Acknowledgments}

The authors thank the Multidisciplinary Laboratory of the Faculty of Medicine and Pharmaceutical Sciences, Department of Pharmaceutical Sciences, for technical and financial 
support. The General Hospital of Douala is acknowledged. Support of Word University Service under APA 2668 for providing the equipment used is appreciated. The authors thank the Association of Commonwealth University for the generous Academic Fellowship CMCF-2015-3. Sincere thanks are expressed to Professor David J. Evans (University of Hull) for his continuous support of our work and helpful discussions.

\section{References}

[1] SumitraChanda, "Silver nanoparticles (medicinal plants mediated): a new generation of antimicrobials to combat microbial pathogens-a review," in Microbial Pathogens and Strategies for Combating Them: Science, Technology and Education, A. Méndez-Vilas, Ed., pp. 1314-1323, 2013.

[2] Willems \& van den Wildenberg, Roadmap Report on Nanoparticles, Associazione italiana per la ricerca industriale/Centro italiano per le nanotecnologie, Rome, Italy, 2005.

[3] N. Cioffi, N. Ditaranto, L. Torsi, and L. Sabbatini, "Approaches to synthesis and characterization of spherical and anisotropic copper nanomaterials," in Nanomaterials for the Life Sciences, S. S. Challa and R. Kumar, Eds., vol. 1 of Metallic Nanomaterials, pp. 3-70, Wiley-VCH, 2009.

[4] N. Pantidos and L. E. Horsfall, "Biological synthesis of metallic nanoparticles by bacteria, fungi and plants," Journal of Nanomedicine \& Nanotechnology, vol. 5, article no. 233, 2014.

[5] D. Bose and S. Chatterjee, "Biogenic synthesis of silver nanoparticles using guava (Psidium guajava) leaf extract and its antibacterial activity against Pseudomonas aeruginosa," Applied Nanoscience, vol. 6, no. 6, pp. 895-901, 2016.

[6] X. Li, H. Xu, Z. Chen, and G. Chen, "Biosynthesis of nanoparticles by microorganisms and their applications," Journal of Nanomaterials, vol. 2011, Article ID 270974, 16 pages, 2011.

[7] F. E. Meva, M. L. Segnou, C. O. Ebongue, V. Deli, J. C. N. Nyobe, and E. M. Mpondo, "Synthesis, optimization and effect of condition reactions studies of seed kernel aqueous extract mediated silver nanoparticles from Ricinodendron heudelotii ${ }_{(B a i l l)}$ Pierre Pax," International Journal of Biosciences (IJB), vol. 7, no. 4, pp. 47-56, 2015.

[8] F. Eyaane Meva, M. L. Segnou, C. Okalla Ebongue et al., "Spectroscopic synthetic optimizations monitoring of silver nanoparticles formation from Megaphrynium macrostachyum leaf extract," Revista Brasileira de Farmacognosia, vol. 26, no. 5, pp. 640-646, 2016.

[9] A. Gomes, S. Ghosh, J. Sengupta, P. Datta, and A. Gomes, "Herbonanoceuticals: a new step towards herbal therapeutics," Medicinal \& Aromatic Plants, vol. 3, article 162, 2014.

[10] M. Murphy, K. Ting, X. Zhang, C. Soo, and Z. Zheng, "Current development of silver nanoparticle preparation, investigation, and application in the field of medicine," Journal of Nanomaterials, vol. 2015, Article ID 696918, 12 pages, 2015.

[11] A. D. Russell and W. B. Hugo, "7 antimicrobial activity and action of silver," Progress in Medicinal Chemistry, vol. 31, pp. 351370, 1994.

[12] F. Eya’ane Meva, M. L. Segnou, C. Okalla Ebongue et al., "Unexplored vegetal green synthesis of silver nanoparticles: a preliminary study with Corchorus olitorus Linn and Ipomoea batatas (L.) Lam," African Journal of Biotechnology, vol. 15, no. 10, pp. 341-349, 2016.
[13] European Society of Clinical Microbiology and Infectious Diseases, Comite de l'Antibiogramme de la Societe Francaise de Microbiologie, vol. 1, ESCMID, Basel, Switzerland, 2015.

[14] J.-P. Ganière, C. Mangion, and M. Péridy, "In vitro determination in milk of the Minimal Inhibitory and Bactericidal Concentrations of celquinone, marbofloxacin, tylosin and spiramycin for bovine mastitis pathogens," Revue de Medecine Veterinaire, vol. 155, no. 8-9, pp. 411-416, 2004.

[15] A. M. Awwad, N. M. Salem, and A. O. Abdeen, "Green synthesis of silver nanoparticles using carob leaf extract and its antibacterial activity," International Journal of Industrial Chemistry, vol. 4, article 29, 2013.

[16] P. Wang, B. Huang, Z. Lou et al., "Synthesis of highly efficient $\mathrm{Ag@AgCl} \mathrm{plasmonic} \mathrm{photocatalysts} \mathrm{with} \mathrm{various} \mathrm{structures,"}$ Chemistry, vol. 16, no. 2, pp. 538-544, 2010.

[17] J. Annamalai and T. Nallamuthu, "Green synthesis of silver nanoparticles: characterization and determination of antibacterial potency," Applied Nanoscience, vol. 6, no. 2, pp. 259-265, 2016.

[18] A. Le, T. T. Le, V. Q. Nguyen et al., "Powerful colloidal silver nanoparticles for the prevention of gastrointestinal bacterial infections," Advances in Natural Sciences: Nanoscience and Nanotechnology, vol. 3, no. 4, Article ID 045007, 2012.

[19] G. M. Sulaiman, W. H. Mohammed, T. R. Marzoog, A. A. A. Al-Amiery, A. A. H. Kadhum, and A. B. Mohamad, "Green synthesis, antimicrobial and cytotoxic effects of silver nanoparticles using Eucalyptus chapmaniana leaves extract," Asian Pacific Journal of Tropical Biomedicine, vol. 3, no. 1, pp. 58-63, 2013.

[20] S. Kheybari, N. Samadi, S. V. Hosseini, A. Fazeli, and M. R. Fazeli, "Synthesis and antimicrobial effects of silver nanoparticles produced by chemical reduction method," DARU Journal of Pharmaceutical Sciences, vol. 18, no. 3, pp. 168-172, 2010.

[21] E. Binaeian, A. M. Rashidi, and H. Attar, "Toxicity study of two different synthesized Silver nano particles on bacteria Vibrio Fischeri," International Journal of Medical,Health, Biomedical, Bioengineering and Pharmaceutical Engineering, vol. 6, no. 7, pp. 517-523, 2012.

[22] T. Stalin Dhas, V. Ganesh Kumar, V. Karthick, K. Jini Angel, and K. Govindaraju, "Facile synthesis of silver chloride nanoparticles using marine alga and its antibacterial efficacy," Spectrochimica Acta - Part A: Molecular and Biomolecular Spectroscopy, vol. 120, pp. 416-420, 2014.

[23] C. Baker, A. Pradhan, L. Pakstis, D. J. Pochan, and S. I. Shah, "Synthesis and antibacterial properties of silver nanoparticles," Journal of Nanoscience and Nanotechnology, vol. 5, no. 2, pp. 244-249, 2005. 

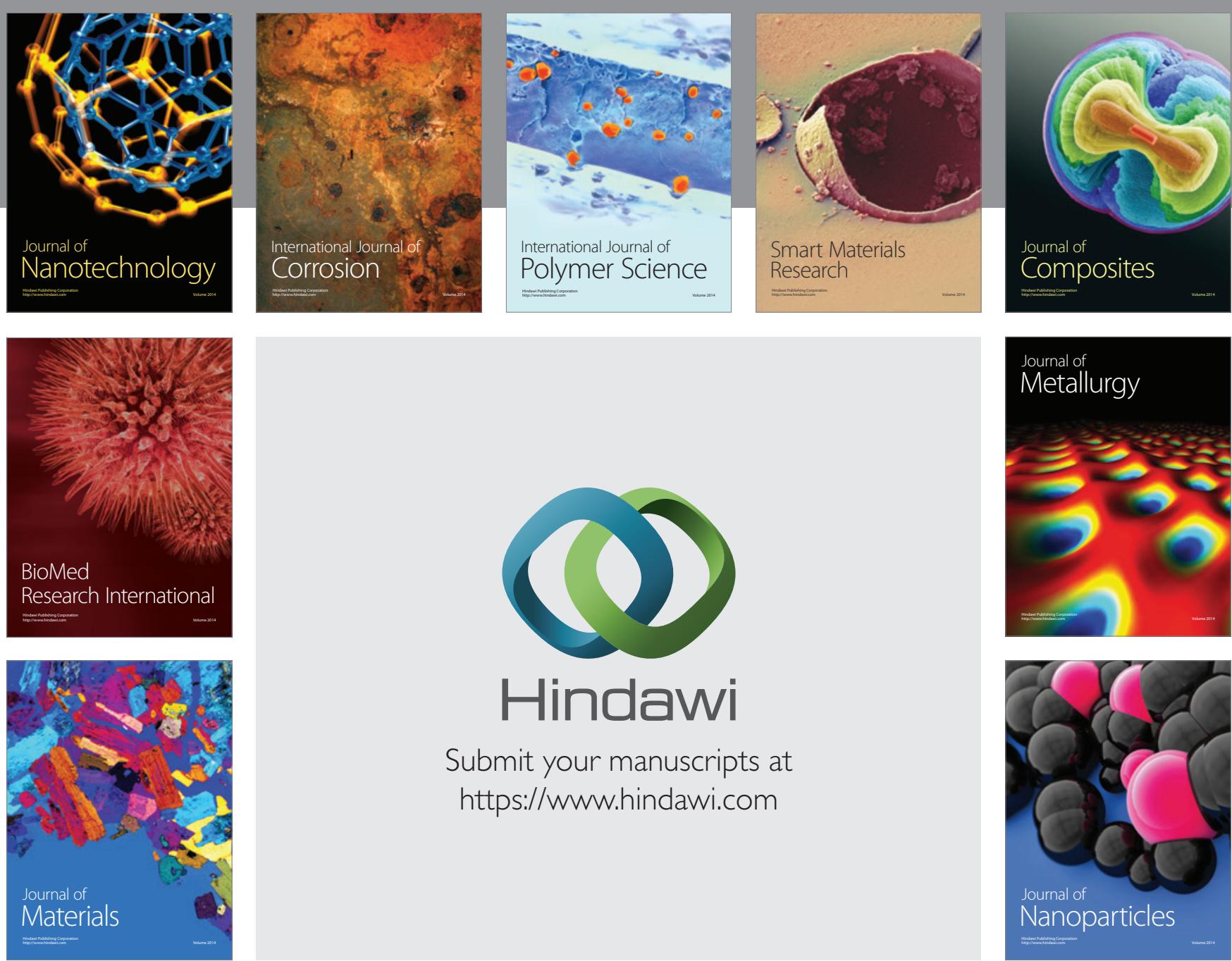

\section{Hindawi}

Submit your manuscripts at

https://www.hindawi.com

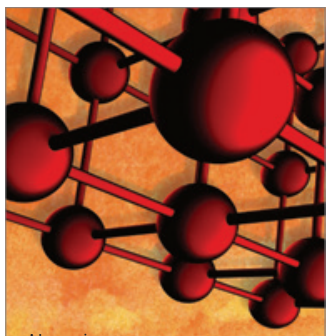

Materials Science and Engineering
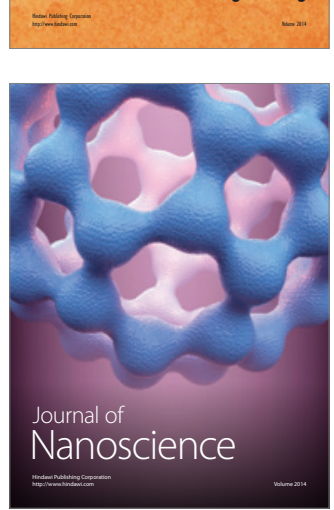
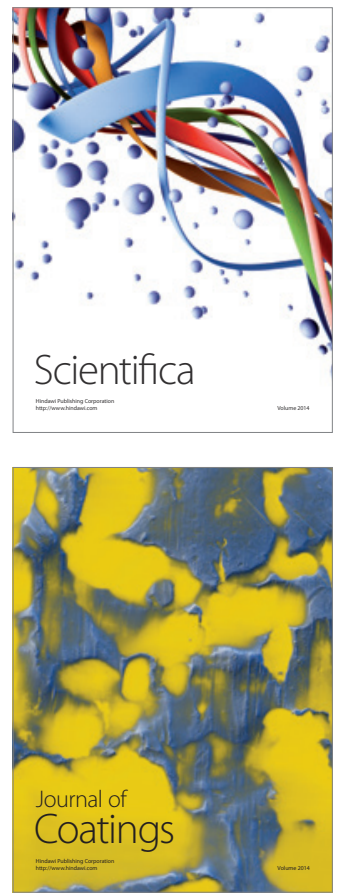
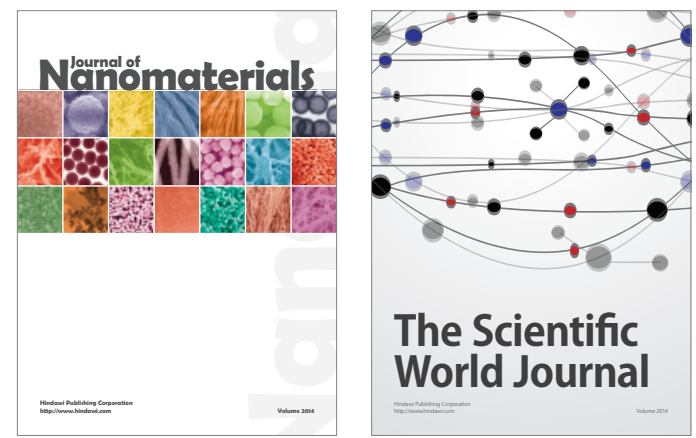

The Scientific World Journal
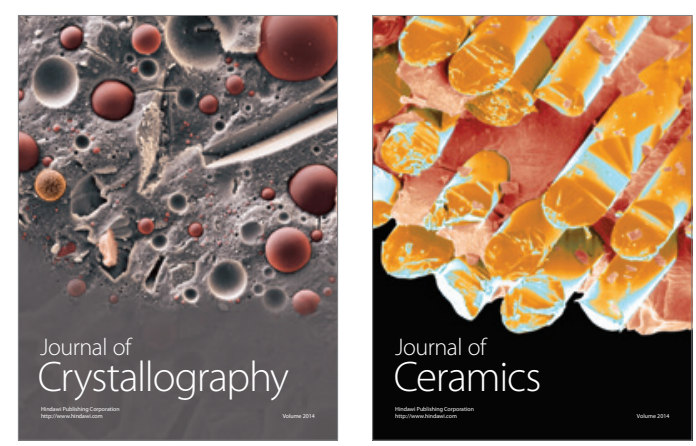
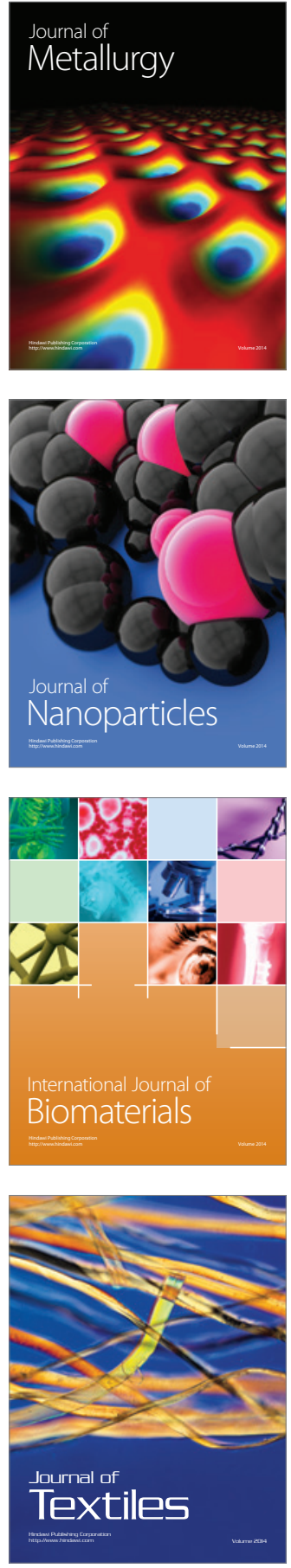